\title{
The Effect of Self-Analysis of the Movement of Running Long Jump Using a Strobe Picture on College Male Students' Performance in PE Class
}

\author{
Kazuhiro Matsui*, Akihiro Azuma \\ Course of General Education (Natural Science), National Institute of Technology, Fukui College, Sabae, Fukui, Japan \\ Email: *matsui@fukui-nct.ac.jp
}

How to cite this paper: Matsui, K., \& Azuma, A. (2021). The Effect of Self-Analysis of the Movement of Running Long Jump Using a Strobe Picture on College Male Students' Performance in PE Class. Advances in Physical Education, 11, 331-339.

https://doi.org/10.4236/ape.2021.113028

Received: May 31, 2021

Accepted: July 18, 2021

Published: July 21, 2021

Copyright (C) 2021 by author(s) and Scientific Research Publishing Inc. This work is licensed under the Creative Commons Attribution International License (CC BY 4.0).

http://creativecommons.org/licenses/by/4.0/

\begin{abstract}
The purpose of this study was to determine the effect of self-feedback by analyzing a strobe picture on jump distance of running long jump in PE class. Subjects are 48 healthy male college students (age: $17.9 \pm 0.4$ years). This study was conducted on five consecutive classes (Days 1 - 5 of the lessons). The maximum jump distances of all subjects were measured, and a strobe picture of the sagittal plane motion from takeoff to landing phase was acquired on Day 4. Subsequently, subjects were taught the biomechanical principles that determine the jump distance and were instructed to derive related biomechanical parameters (physics variables) from their own strobe pictures using digitizing software. On Day 5, the maximum jump distances of subjects while considering their feedback were measured, and strobe pictures of the movement were acquired again to derive their physics variables after the feedback. Results showed that, on average, there were no significant changes in the jump distance or to the physics variables before and after feedback. However, by analyzing the subjects whose jump distance increased or decreased after the feedback, it was observed that this feedback may improve the performance of learners whose jump distances were initially not so far and/or learners who cannot utilize their sprint abilities effectively to initial speed at takeoff.
\end{abstract}

\section{Keywords}

Running Long Jump, Self-Analysis, Feedback, Strobe Picture, PE Class

\section{Introduction}

Video or movie is one of the effective instructional tools that can be used in sports (James, 1971; Neufeld \& Neufeld, 1972; Sewall et al., 1988; Van Wieringen et al., 
1989) as well as in physical education (PE) classes (Weir \& Connor, 2009; Fukkink et al., 2011). Movies also deepen the PE learner's recognition of the movement (Azuma et al., 2004). Moreover, it has been reported that videos would enable understanding and sharing of movement or lead to appropriate skill acquisition in sports through visual feedback (Rohleder \& Vogt, 2018; Shishido \& Hashimoto, 2019). Tablet-type devices equipped with cameras allow the easy record and play of movies, and learners themselves are increasingly using these devices in physical education (PE) classes (Sinelnikov, 2012). In addition, this process has been enhanced by advances in software that facilitates the efficient analysis and editing of digital pictures and movies.

Feedback of sports performance using movies is well known to be effective in improving the movement, especially in closed-skill type sports such as track and field, gymnastics, or swimming (Cooper \& Rothstein, 1981). It has also been reported that providing biomechanical parameters such as velocity or angle (henceforth, physics variables) can also be an efficient feedback for improving the movements in these types of sports (Gorman et al., 2019). Generally, operating skills using a motion analysis device are a prerequisite for the acquisition of physics variables, and hence, it is difficult for athletes or learners to obtain biomechanical parameters easily and use them in practice subsequently. However, a portable recording device (such as a tablet-type device) along with appropriate software might enable learners to carry out a simple motion analysis. From this viewpoint, Matsui and Azuma (2019) attempted a running-long jump PE class based on biomechanical feedback which learners could enhance their understanding of their movements and provide learners to simple physics variables, using a strobe picture digitizing software.

Because strobe pictures are continuously depicted after-images of movements at a given time interval within an image, the trajectory of a specific point of the body can be tracked by using a digitizing software that enables the analysis of two-dimensional coordinates. Matsui and Azuma (2019) instructed the learners in engineering courses with physics knowledge (including oblique projection) to analyze the initial velocity at takeoff, takeoff angle, and height of the greater trochanter (GT) at landing in running-long jump through digitizing GT marker. Such provided a movement feedback. Results showed that, on average, there was no significant improvement in performance. However, the jump distance tended to increase especially for learners with greater jumping skills. This study was expected to improve learners' movement as a result of their improved understanding of the movement of physics-related concepts (i.e., oblique projection). However, small-effect mentioned above might reflect, in fact, an inadequate understanding of movement due to the lack of sports science knowledge before feedback. Particularly, as takeoff angle in jumpers as a biomechanical knowledge can provide more useful information than the oblique projection theory (Fukashiro, 1983), it should be given to the learner opportunities of self-feedback and biomechanical information at the same time. 
Therefore, the purpose of this study was to examine the effects of self-feedback of takeoff movement using a strobe picture analysis with its biomechanical knowledge on the jump distance in running-long jump PE class.

\section{Methods}

\subsection{Subjects}

Subjects included in this study were 48 healthy male college students (age: $17.9 \pm$ 0.4 years, stature: $173.1 \pm 5.4 \mathrm{~cm}$, weight: $63.0 \pm 8.4 \mathrm{~kg}$ ), with no history of injuries on lower extremities that would interfere with running long jump. The subjects were third-year students studying technology and engineering in KOSEN, a college for five-year engineer education in Japan, who had already taken fundamental physics (including projectile motion) in the first and second years. This study was conducted in a regular PE class, and all subjects were participants of the class. The purpose, methods, and possibility of using data for publication of this study were adequately explained beforehand, and written consent was obtained from all subjects. The Research Ethics Committee approved this study of the National Institute of Technology, Fukui College (Reference number: 30-1 and 31-2).

\subsection{Procedure}

This study consisted of a five-day series of running long jump classes (Table 1: Day 1 - 5). In Day 1, a basic guidance was provided, and subjects practiced standing jump, stepping using a springboard, and landing into a sandpit. On Days 2 and 3, the subjects practiced jumping with a step-by-step increase in the distance of the approach run. In the final stage on Day 3, the subjects set their distance of approach run and tried to perform a maximum jump. On Day 4, maximal jump distances were measured. The sagittal plane movements of jumping during the period from takeoff to landing were recorded using Pad $^{\circledR}$ (A1701 model, Apple Inc.) in which the strobe picture editing software, Clipstro (Ver. 3.1.6, SPLYZA Inc.) was installed beforehand.

Table 1. Sequence of the contents in running-long jump class.

\begin{tabular}{|c|c|}
\hline Day \# & Contents \\
\hline Day 1 & Practicing standing or stepping jump and landing. \\
\hline Day 2 & Practicing long jumping while increasing approach-run distance. \\
\hline Day 3 & Practicing long jumping for setting a full approach-run distance. \\
\hline Day 4 & $\begin{array}{l}\text { Measurement of jump distance plus providing biomechanical knowledge } \\
\text { (Before self-analysis for the feedback). }\end{array}$ \\
\hline \multirow{3}{*}{ Day 5} & Assignment 1: Self-analysis for the feedback \\
\hline & Measurement of jump distance (After self-analysis for the feedback). \\
\hline & Assignment 2: Self-analysis for the reflection \\
\hline
\end{tabular}




\subsubsection{Biomechanical Knowledge Provided to Subjects}

After measuring and recording on Day 4, subjects were then given the knowledge about the biomechanical factors determining the jump distance in running long jump. The relationship between the initial velocity of the body's center of gravity at takeoff and takeoff angle was explained using paper-based material, according to Fukashiro (1983). Furthermore, participants were provided with a brief review of oblique projection to revisit the knowledge acquired already during their physics classes. Additionally, the following equation for the estimation of jump distance $(L)$ was shown in the material:

$$
L=v_{0} \operatorname{con} \theta \cdot \frac{v_{0} \sin \theta+\sqrt{v_{0} \sin \theta^{2}+2 g H}}{g},
$$

where $v_{o}$ is the initial velocity at takeoff, $\theta$ is the takeoff angle, $H$ is the difference of the GT height between takeoff and landing, and $g$ is the acceleration of gravity (Figure 1). The captured movie was processed using an application software, Clipstro, to create a strobe image in JPEG format. Next, each subject was instructed the process to analyze the strobe images of their own picture (1st strobe picture) to acquire feedback data. The strobe images were provided via a USB flash drive containing the digitizing software WebPlotDigitizer (produced by Ankit Rohatgi) and an analysis spreadsheet (Microsoft ${ }^{\circledR} \operatorname{Excel}^{\circledR}$ 2016). Although WebPlotDigitizer is a free software, it has been widely used in image analysis, including medical papers, and many reports have shown the accuracy of coordinate conversion and reliability of angle calculation (Carlson et al., 2016; Mani et al., 2018).

\subsubsection{Comparison of Movements before and after Feedback}

The maximal jumping on Day 5 was made by the subjects being conscious of the feedback. Also, a strobe picture (2nd strobe picture) on Day 5 was provided to each subject, and they were instructed to analyze the strobe picture again to compare it with the first analysis. Furthermore, subjects were required to describe their introspections on a reflection sheet for these two analyses.

\subsection{Analysis}

Jump distance, initial velocity at takeoff, takeoff angle, and GT height at landing before the first feedback (based on the 1st strobe picture) were compared with those data acquired from the second feedback (based on the 2nd strobe picture). The relationship between the change in delta jump distance $(\Delta J \mathrm{D})$ and the change in physics variables was investigated. In addition, subjects were divided into two groups, one with an increase in jump distance (JD-Up group, $\mathrm{n}=21$ ) and a decrease in jump distance (JD-Down group, $\mathrm{n}=27$ ). Differences in jump distance and physics variables before and after the analysis were compared in these two groups.

\subsection{Statistics}

A paired t-test was used to examine the differences among the average values of 


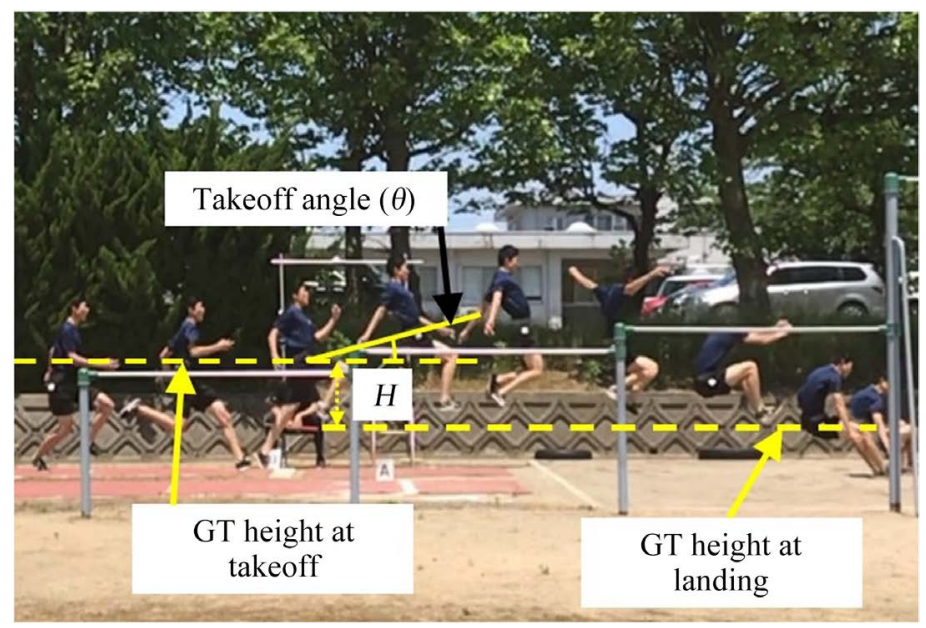

Figure 1. A strobe picture used in this study, and parameters led by self-analysis.

jump distance, initial speed at takeoff, takeoff angle, and GT height at landing before and after feedback. The relationship between $\triangle J D$ and the change in initial speed at takeoff, takeoff angle, and GT height at landing was determined using Pearson's product-moment correlation coefficient (delta means after-before). Two-way repeated-measures analysis of variance (ANOVA) was used to compare the initial speed at takeoff, takeoff angle, and GT height at landing for before and after the first self-analysis (for the feedback) in the JD-Up and JDDown groups, and the Holm method was used as the post-hoc test. All statistical significance levels were set at $5 \%$.

\section{Results}

On average, there was no significant difference $(P>0.05)$ in jumping distance, initial speed at takeoff, takeoff angle, and GT height at landing before and after the (first) feedback. In addition, the correlation coefficients ( $r$ ) between $\triangle \mathrm{JD}$ and the change in each parameter in jump distance were not significant at 0.195 (initial speed at takeoff), 0.008 (takeoff angle), and -0.13 (GT height at landing).

In contrast, Table 2 showed the results of a two-way ANOVA. Although the main effects of between-groups analysis and the feedback acquired were not significant for jump distance, the interaction proved to be highly significant $(P<$ 0.05). A difference between-groups were found before the feedback (JD-Up group $<$ JD-Down group). The jump distance increased for the JD-Up group after the feedback, as opposed to the JD-Down group for which the jump distance was decreased. The main effect in the initial speed at takeoff was significant only between the groups (JD-Up group $<$ JD-Down group, $P<0.05$ ). Moreover, interaction was also significant $(P<0.05)$; i.e., there was a difference between the groups before feedback (JD-Up group $<$ JD-Down group) and between before and after feedback (before $<$ after) in the JD-Up group (both $P<0.05$ ). The main effect and interaction were not significant for takeoff angle and GT height at landing. 
Table 2. Means \pm SDs and results of two-way ANOVA.

\begin{tabular}{|c|c|c|c|c|c|c|}
\hline \multirow{2}{*}{ Variables } & \multirow{2}{*}{$\begin{array}{l}\text { Before } \\
\text { /After }\end{array}$} & \multirow{2}{*}{$\begin{array}{l}\text { JD-Up group } \\
\quad(\mathrm{n}=21)\end{array}$} & \multirow{2}{*}{$\begin{array}{l}\text { JD-Down group } \\
\quad(\mathrm{n}=27)\end{array}$} & \multicolumn{2}{|c|}{ Main effects } & \multirow{2}{*}{ Interaction } \\
\hline & & & & Group & Before/After & \\
\hline \multirow[t]{2}{*}{ Jump distance (m) } & Before & $3.77 \pm 0.34$ & $4.18 \pm 0.47^{\mathrm{a}}$ & \multirow[b]{2}{*}{ n.s. } & \multirow[b]{2}{*}{ n.s. } & \multirow[b]{2}{*}{$P<0.05$} \\
\hline & After & $4.00 \pm 0.32^{\mathrm{b}}$ & $3.94 \pm 0.50^{c}$ & & & \\
\hline \multicolumn{7}{|l|}{ Feedback parameters } \\
\hline \multirow{2}{*}{ Speed $(\mathrm{m} / \mathrm{s})$} & Before & $3.34 \pm 0.43$ & $3.64 \pm 0.40^{\mathrm{a}}$ & \multirow{2}{*}{$P<0.05$} & \multirow{2}{*}{ n.s. } & \multirow{2}{*}{$P<0.05$} \\
\hline & After & $3.54 \pm 0.35^{\mathrm{b}}$ & $3.57 \pm 0.50$ & & & \\
\hline \multirow{2}{*}{ Angle (degree) } & Before & $12.9 \pm 5.1$ & $13.5 \pm 5.2$ & \multirow[b]{2}{*}{ n.s. } & \multirow[b]{2}{*}{ n.s. } & \multirow{2}{*}{ n.s. } \\
\hline & After & $15.2 \pm 4.3$ & $14.5 \pm 4.4$ & & & \\
\hline \multirow{2}{*}{ GT height (m) } & Before & $0.83 \pm 0.08$ & $0.85 \pm 0.11$ & \multirow[b]{2}{*}{ n.s. } & \multirow[b]{2}{*}{ n.s. } & \multirow[b]{2}{*}{ n.s. } \\
\hline & After & $0.82 \pm 0.08$ & $0.85 \pm 0.13$ & & & \\
\hline
\end{tabular}

"n.s." indicates no significant. ${ }^{a}$ significant between JD-Up and JD-Down groups in before feedback. ${ }^{\mathrm{b}}$ significant between before and after feedbacks in JD-Up group. ${ }^{c}$ significant between before and after feedbacks in JD-Down group.

\section{Discussion}

\subsection{Overall Trend of the Feedback Effect}

This study was conducted in a running-long jump PE class in which learners (subjects) could deeply understand and improve their performance through self-feedback (on initial velocity at the time of takeoff, takeoff angle, and GT height at landing) stemming from a strobe picture of their long jumps. However, on average, jump distance did not change significantly, and the physics variable parameters were also not improved. In this study, biomechanical knowledge on these parameters was provided to the subjects beforehand. It was expected that the data derived from the feedback would enable subjects to understand their movements and improve their performance deeply.

In this study, we practically investigated how learners tried to improve their movements in the PE class through self-analysis feedback. That was a reason why this study differed from an experimental research design that examines the effects of self-analysis from changes in performance by setting an experimental and a control group. Also, the learners' self-analysis (in physics variables) was used as one of the research targets, and the learners were made to analyze the movement (using a 2nd strobe picture) after the feedback to obtain their introspections via reflection sheet. Thus, this study can be recognized as a quantitative lesson study to introduce self-analysis feedback into PE classes.

Findings in this study are similar to the results of Matsui and Azuma (2019), where the self-feedback (analyzing a strobe picture) was performed without prior biomechanical knowledge, and no changes in performance or parameters were showed after the feedback. Furthermore, the correlations between the change in jump distance $(\Delta J D)$ and the change in each parameter were also not significant. Generally, the averages or simple correlations used to be statistical methods that represent the trend of the entire population and thus fail to reveal whether there 
are any subgroups for which the feedback worked (or did not) effectively. It is necessary to evaluate the specific groups brought and the specific (physical) factors that facilitate subjects' performance changes because observed individual differences in performance or parameter changes were far from negligible.

\subsection{Comparison of the Feedback Effect among Groups}

A two-way ANOVA was carried out from this point of view for two factors: i.e., group (JD-Up group vs. JD-Down group) and the before/after the feedback. The increase in the jump distance of the JD-Up group after feedback was considered to be shown to be due to the smaller jump distance in the JD-Up group before feedback (interaction was significant). Hence, the effect of feedback was observed in subjects with low initial levels of jump distance.

In contrast, feedback with respect to the initial speed at takeoff seemed to be observed in subjects (JD-Up group) with low initial speed before feedback (interaction was significant). Referring to the introspection from their reflection sheets, it was found that the subjects in both groups were equally conscious of trying to improve their initial speed based on the feedback (approximately half of the subjects; JD-Up group: 43\%, JD-Down group: 50\%). Furthermore, the effect of feedback on initial speed was not considered to be due to the difference in their consciousness. In addition, as there was no significant difference in 50-m run time between the groups (JD-Up group: $8.63 \pm 1.60 \mathrm{~s}$ vs. JD-Down group: $8.24 \pm 1.22$ s), it was suggested that the JD-Up group might not be able to develop their (true) running ability during the approach-run phase. In other words, the effect of the feedback on the initial speed might have appeared in subjects who had not achieved the speed in the approach-run phase. Furthermore, it might be easier to increase the speed of the approach run and the initial speed at takeoff by maximizing the students' inherent running ability, instead of increasing the takeoff angle, which requires a change in movement.

Two-way ANOVA did not reveal any significant changes as a result of the interaction in the takeoff angle and GT height at landing. Because the initial speed at takeoff and takeoff angle is interrelated, it is difficult to increase both parameters (Fukashiro, 1983). However, even though the initial speed at takeoff increased after feedback in the JD-Up group, there was no change in the takeoff angle. This suggests that the JD-Up group, in which the initial velocity was increased as opposed to the takeoff angle that remained unchanged, was considered to be leading in improvement by the equation of projectile motion.

\subsection{Position and Perspective of This Study}

Matsui and Azuma (2019) reported the effect of self-feedback in a strobe picture on learners with low-jumping skills regarding the speed-effectiveness index, which expresses jumping skill. In our study, such feedback might be effective in learners whose jumping distances were not long and those who failed to further improve their running ability in approach run. 
Although the effectiveness of videos in PE classes has been well known (Weir \& Connor, 2009; Fukkink et al., 2011), studies on how learners utilize the videos as feedback are limited (Matsui \& Azuma, 2019). This study ameliorates the previous method (Matsui \& Azuma, 2019), as learners were given biomechanical knowledge beforehand and then were able to make jumps based on their selfanalysis. Consequently, new knowledge was added to our previous work (Matsui \& Azuma, 2019). Hence, it is expected that the basis of this study is helpful to develop teaching techniques that enable PE learners, especially those who have low skills of the movement, to more easily analyze biomechanical parameters (as pointed out by Gorman et al., 2019), which will lead to self-learning or active learning.

\section{Conclusion}

In this study, we evaluated the effect of self-analysis (feedback) to derive physics variables from a strobe picture on long jump performance in a running long jump class. The results showed that, on average, there were no performance changes on the derived physics variables before and after the feedback among PE learners. However, it is suggested that such feedback may improve the performance of learners whose jump distance is not long and/or learners who cannot further improve their running ability in the approach run. Therefore, self-analysis of a strobe picture had a limited effect on PE regarding running long jump.

\section{Conflicts of Interest}

The authors declare no conflicts of interest regarding the publication of this paper.

\section{References}

Azuma, A., Nishikawa, Y., Okuyama, J., Sugimoto, N., Mitani, C., \& Katoh, T. (2004). Effects of the Instruction of Walking in Water for the Middle-Aged Using Digital Movies in Computer and Paper-Based Materials on the Recognition of Exercise Intensity. Japanese Journal of Physiological Anthropology, 9, 115-120. (In Japanese)

Carlson, V. R., Sheehan, F. T., \& Boden, B. P. (2016). Video Analysis of Anterior Cruciate Ligament (ACL) Injuries: A Systematic Review. JBJS Reviews, 4, Article No. e5. https://doi.org/10.2106/JBJS.RVW.15.00116

Cooper, L. K., \& Rothstein, A. L. (1981). Videotape Replay and the Learning of Skills in Open and Closed Environments. Research Quarterly for Exercise and Sport, 52, 191-199. https://doi.org/10.1080/02701367.1981.10607857

Fukashiro, S. (1983). Hashirihabatobi to Sandantobi No Biomechanics (Biomechanics of Running Long Jump and Triple Jump). Japanese Journal of Sports Sciences, 2, 600-613. (In Japanese)

Fukkink, R. G., Trienekens, N., \& Kramer, L. J. C. (2011). Video Feedback in Education and Training: Putting Learning in the Picture. Educational Psychology Review, 23, 4563. https://doi.org/10.1007/s10648-010-9144-5

Gorman, A. J., Willmott, A. P., \& Mullineaux, D. R. (2019). The Effects of Concurrent Biomechanical Biofeedback on Novel Skill Acquisition. Sports Biomechanics, 26, 1-15. 


\section{https://doi.org/10.1080/14763141.2019.1650101}

James, P. E. (1971). Video Feedback in Learning Beginning Trampoline. Perceptual and Motor Skills, 32, 669-670. https://doi.org/10.2466\%2Fpms.1971.32.2.669

Mani, S., Sharma, S., \& Singh, D. K. A. (2018). Web Plot Digitizer Software: Can It Be Used to Measure Neck Posture in Clinical Practice? Asian Journal of Pharmaceutical and Clinical Research, 11, 86-87.

Matsui, K., \& Azuma, A. (2019). A Study on Self-Analysis of the Movement Using a Strobe Picture: Its Effect on College Male Students' Long Jump Performance. Research Reports of National Institute of Technology, Fukui College, Natural Science and Engineering, 53, 29-34. (In Japanese)

Neufeld, M. M., \& Neufeld, R. W. (1972). Use of Video-Tape Feedback in Swimming Instruction with Emotionally Disturbed Children. Perceptual and Motor Skills, 35, 992. https://doi.org/10.2466\%2Fpms.1972.35.3.992

Rohleder, J., \& Vogt, T. (2018). Teaching Novices the Handstand: A Practical Approach of Different Sport-Specific Feedback Concepts on Movement Learning. Science of Gymnastics Journal, 10, 29-42.

Sewall, L. P., Reeve, T. G., \& Day, R. A. (1988). Effect of Concurrent Visual Feedback on Acquisition of a Weightlifting Skill. Perceptual and Motor Skills, 67, 715-718. https://doi.org/10.2466\%2Fpms.1988.67.3.715

Shishido, T., \& Hashimoto, M. (2019). Using ICT to Enhance Student Engagement in Physical Education: The Effects of Visual Feedback Displaying the Students' HR on a Monitor during Endurance Running. Journal of Human Environmental Studies, 17, 4550. (In Japanese) https://doi.org/10.4189/shes.17.45

Sinelnikov, O. A. (2012). Using the iPad in a Sport Education Season. Journal of Physical Education, Recreation and Dance, 83, 39-45. https://doi.org/10.1080/07303084.2012.10598710

Van Wieringen, P. C. W., Emmen, H. H., Bootsma, R. J., Hoogesteger, M., \& Whiting, H. T. A. (1989). The Effect of Video-Feedback on the Learning of the Tennis Service by Intermediate Players. Journal of Sports Sciences, 7, 153-162. https://doi.org/10.1080/02640418908729833

Weir, T., \& Connor, S. (2009). The Use of Digital Video in Physical Education. Technology, Pedagogy and Education, 18, 155-171. https://doi.org/10.1080/14759390902992642 